DEPARTMENT OF ECONOMICS

OxCarre (Oxford Centre for the Analysis of Resource Rich Economies)

Manor Road Building, Manor Road, Oxford OX1 3UQ

Tel: +44(0)1865 281281 Fax: +44(0)1865 281163

UNIVERSITY OF

reception@economics.ox.ac.uk www.economics.ox.ac.uk

OXFORD

OxCarre Research Paper 73

\title{
On Equilibrium in Resource Markets with Scale Economies and Stochastic Prices
}

\author{
Charles F Mason* \\ University of Wyoming
}

*External Research Associate, OxCarre 


\title{
On Equilibrium in Resource Markets with Scale Economies and Stochastic Prices
}

\author{
Charles F. Mason ${ }^{\dagger}$ \\ H.A. True Chair in Petroleum and Natural Gas Economics \\ Department of Economics \& Finance \\ University of Wyoming, \\ 1000 E. University Ave. \\ Laramie, WY 82071
}

September 15, 2011

\begin{abstract}
I consider a non-renewable resource market where extraction costs are non-convex and market price is subject to stochastic shocks. While competitive equilibrium cannot exist if costs are non-convex and demand is deterministic, equilibrium can be supported in the context of stochastic demand. The crucial distinction is that the noisy environment can create an incentive for firms to hold inventories. Inventories allow firms to continue producing at a smooth pace at any instant when extraction ceases, e.g. when reserves are exhausted. Accordingly, there are no abrupt changes in the expected price path, in contrast to the deterministic variant of the model.
\end{abstract}

Keywords: Resource Economics, Stochastic Dynamic Optimization

JEL Areas: Q2, D8, L15

\footnotetext{
$\dagger$ phone: +1-307-766-2178; fax: +1-307-766-5090; e-mail: bambuzlr@uwyo.edu. I have benefited from the remarks of Bob Cairns, Roger Craine, John Hartwick, Todd Sandler, Steve Salant, Joe Swierzbinski and seminar participants at the Universities of Michigan and Wyoming. I am particularly grateful to Steve Polasky for stimulating conversation. Two referees and the guest editor provided critical feedback that substantially improved the manuscript. Yang Lu provided excellent research assistance. Any remaining errors are my responsibility.
} 


\section{Introduction}

Over the past three decades, a number of papers have investigated the implications of non-convex production costs for competitive equilibria in markets for non-renewable resources (Oleweiler, 1981; Eswaran et al., 1983; Hartwick et al., 1986; Cairns, 1991; Asheim, 1992; Lozada, 1996; Fisher, 2005). A common theme that arises in this literature is that the existence of scale economies and perfect foresight regarding prices is incompatible with the existence of a competitive equilibrium, a point first made by Eswaran et al. (1983) (hereafter, ELH). ELH establish this non-existence result by showing that i) an equilibrium must entail firms extracting at a rate which intertemporally equates rents (i.e., firms follow the Hotelling (1931) "r-percent rule"); ii) firms who follow such a program will discontinuously change production at some terminal time, reducing their extraction rate from that which minimizes average cost (where average cost equals marginal cost) to zero; and iii) with all firms following such a program, there will be a jump discontinuity in price at the terminal time, so that each firm could improve its value by delaying exhaustion of its reserves. It then follows that no equilibrium can exist. ${ }^{1}$

This gloomy message appears to be at odds with the observation that there are well-

\footnotetext{
1 Lozada (1996) extends this result to allow for heterogeneous firms. In principle, equilibrium could be retrieved if firms employed "chattering controls", whereby they instantaneously switch between producing nothing and producing some positive level, thereby convexifying their problem. Both ELH and Lozada rule out chattering controls by assuming extraction paths are piecewise continuous, or equivalently "that there are non-zero adjustment costs associated with changing the extraction rate by some discrete amount from one instant to the next" (Eswaran et al., 1983, p. 157). The empirical relevance of chattering controls seems limited because it is generally costly to close down and re-open a mine or production well. Anecdotal evidence supporting this point can be found in the U.S. Natural Gas market. For most of 2002 and 2007 the spot prices of Natural Gas at trading hubs in the state of Wyoming were well below the trading price at Henry's Hub (generally thought of as the benchmark for the U.S. market); in 2007, this differential was often in the range of $\$ 4$ per mcf, roughly $80 \%$ of the spot price at Henry's Hub. In both years, the differential was widely regarded as resulting from insufficient pipeline capacity leaving the state of Wyoming, and in both years the price differential disappeared following pipeline capacity expansion. As a result, it seems reasonable that agents would have anticipated sharp increases in spot prices at Wyoming trading hubs as the new capacity was being built in 2007. But most Wyoming producers elected to leave their wells in continual operation during 2007, typically claiming that the cost of 'shutting in' production would be unacceptably large. The fact these producers were willing to forego what were likely to be significant increases in revenues suggests that there were in fact important costs associated with making discrete changes to extraction rates (either in shutting off production or in restarting it).
} 
functioning markets for both current and future delivery of a large variety of non-renewable resources. The non-existence result could be reconciled with the empirical evidence in a variety of ways. Perhaps the production of these resources is not subject to non-convex costs. Perhaps agents do not employ rational expectations. Perhaps there is a backstop technology with cutoff price at or below the terminal price in the optimal program outlined above. Perhaps strategic considerations are underlying current behavior, with such behavior being part of a non-cooperative equilibrium (Cairns, 1991; Asheim, 1992; Fisher and Karp, 1993). None of these explanations is very palatable as a broad explanation, however.

Scale economies in production appear to be an important phenomenon for many nonrenewable resources. These economies can be manifested in the presence of persistent fixed costs, for example when there are irretrievable investments in mining capacity, or because of efficiencies obtained by expanding existing mines. The empirical relevance of scale economies has been well-documented for a variety of resources (CRA, 1977; Mason, 1989; Zimmerman, 1977). ${ }^{2}$ The hypothesis that agents are simply myopic, or dumb, is facile. Similarly, it is hard to believe that, serendipitously, a cutoff price for a backstop just happens to prevent a jump in prices when firms' reserves tap out. Appealing to a non-cooperative framework may have appeal for some resources, but it would require all firms to employ strategic behavior: if a competitive fringe existed, the market price would still jump when their participation ended. ${ }^{3}$ Even if all firms did employ the

\footnotetext{
2 The scale economies I envision are characterised by U-shaped average cost curves. Such cost curves could result because of important fixed costs or because marginal costs are declining at smaller outputs, but rising at larger outputs. I do not distinguish between these types of non-convexities.

3 Unless the remaining firms took actions to offset the jump. The plausibility of such actions is questionable: For example, while one might argue that crude oil markets are not competitive, with member states of OPEC playing the role of oligopolists, it seems unlikely that agents anticipate part of all of OPEC stepping into a void filled by firms that instantaneously switch from positive to zero production. One need only investigate crude oil spot markets in February 2011, around the time of the uprising in Libya, for evidence on this point. When Libyan production dropped dramatically spot prices, particularly in Europe, rose sharply. And while the Saudis did eventually increase production to fill this gap it took them weeks to do so. Accordingly, I do not believe the conjecture that elements in OPEC might offset rapid drops in production is convincing.
} 
putative equilibrium strategies, existence of equilibrium depends on the particular behavioral assumptions invoked (Cairns, 2008). Since many markets for natural resources are characterized by large numbers of firms extracting the ore ${ }^{4}$ the oligopoly story seems unconvincing as a generic explanation.

There is an alternative explanation, which I believe is more empirically compelling. As the analyses in the extant literature are couched in terms of deterministic frameworks, it is natural to ask if the presence of demand shocks would resolve the non-existence phenomenon. In such a context, can a rational expectations equilibrium obtain? In this paper, I incorporate such a random process into a model of a non-renewable resource market where extraction is characterized by scale economies, and investigate the resultant implications for existence of equilibrium.

The key to the recovery of equilibrium in a noisy environment is inventory holdings. ELH demonstrated that firms have no incentive to hold inventories in a deterministic world. To induce firms to hold stockpiles in a deterministic world, prices would have to rise at the rate of interest. But if prices adjusted at such a rate, rents would rise at a rate in excess of the interest rate. This would imply that firms have an incentive not to extract, so that there would be no fodder from which to build inventories. In contrast, if prices are driven by a random process, then firms may have an incentive to hold inventories. This motive stems from the fact that demand shocks induce fluctuations in market price, which will lead to variations in the firm's optimal extraction rate. So long as there is enough variation in production, relative to the overall downward trend that must occur for non-renewable resources, and if marginal cost is increasing in production, firms will wish to hold inventories to guard against future increases in costs (Arrow et al., 1958; Blanchard and

\footnotetext{
4 For example, there are thousands of firms participating in the U.S. Natural Gas market; indeed, the largest producer (Exxon-Mobil) only accounts for roughly $0.6 \%$ of the U.S. market.
} 
Fisher, 1989). This will be true no matter what current price is, and no matter what the current level of resources in situ. The existence of inventories allows production smoothing at any critical point in time where firms switch from actively extracting to not extracting. A plausible conjecture, then, is that the presence of stochastic prices facilitates the existence of a competitive equilibrium by virtue of the motive it creates to hold inventories.

As an empirical point, inventory holdings are important for many non-renewable resources. In Figure 1, I illustrate annual inventory time series for nine natural resources. ${ }^{5}$ These resources share some important common features: non-trivial levels of private stockpiles were held over a long time period for each resource, could be quite large in magnitude, and often displayed substantial variation over time. While there are some differences in the patterns over time, and while there have been marked reductions in inventory holdings for some resources, there is no disputing the broad empirical importance of natural resource inventories. This stands in stark contrast to the absence of motives for holding inventories in a deterministic model, and highlights the potential relevance of inventory holdings as a mitigating factor against ELH's non-existence argument.

The paper commences with a discussion of the model in section 2 . I then analyze the optimal behavior from the firm's point of view in section 3. The motivation to hold inventories is evaluated in section 4. I discuss the implications for price paths that emerge from optimizing behavior, and consider the conditions for equilibrium to exist in section 5. I discuss a variety of extensions in section 6, and offer concluding remarks in section 7.

\footnotetext{
5 The data for these figures was taken from the United States Geologic Survey website, which can be accessed at http://minerals.usgs.gov/minerals/pubs/commodity/. Here, one can find data for a wide range of minerals. The resources included in Figure 1 have data over a reasonably long time frame, and are representative of the broader sample. The resources illustrated are: Beryllium, Cobalt and Helium (first row); Lead, Molybdenum and Quartz Crystals (second row); Soda Ash, Sulfur and Zinc (bottom row). Other authors have found similar patterns to those ilustrated here: Stockpiles of copper and heating oil are commonly 150\% - 300\% of annual consumption (Pindyck, 1994; Thurman, 1988). Similarly, inventory holdings are important in markets for coal, gold, silver, uranium, and petroleum products (Williams and Wright, 1991).
} 


\section{A Model With Scale Economies and Stochastic Prices}

In this section, I develop a continuous time model of a non-renewable resource industry where extraction costs are non-convex, and prices follow a random process. To this end, I incorporate aspects of the models previously studied by Pindyck (1980, 1982); Dixit and Pindyck (1993) and Mason (2001). The industry is composed of $N$ firms, where $N$ is sufficiently large that each firm may regard itself as insignificant. These firms are identical at time zero: the resource is homogeneous, each firm has the same cost function, and all firms start with initial reserves of $R_{0} .{ }^{6}$ Firm $i$ chooses an extraction rate, $y_{i t}$, and a sales rate, $q_{i t}$, at each instant $\mathrm{t}$ to maximize the discounted flow of its profits. Firm $i$ 's reserves at instant $t$ are $R_{i t}$; these reserves decumulate at a rate equal to the selected extraction rate. Firms may elect to hold inventories; I denote firm i's period $t$ inventory holding as $S_{i t}$. All firms start with no inventories. Inventories accumulate according to the difference between extraction and sales, $w_{i t}=y_{i t}-q_{i t}$. It will be convenient to focus on net additions to inventories rather than sales; thus, I use $y_{i t}$ and $w_{i t}$ as the firm's control variables. The equations of motion for the firm's remaining reserves and inventories are:

$$
\begin{aligned}
\dot{R}_{i t} & =-y_{i t} \\
\dot{S}_{i t} & =w_{i t} .
\end{aligned}
$$

The set of feasible controls is $\{(y, w): y \geq 0, w \leq y\}$, where $w=-\infty$ implies instantaneous liquidation of current inventories. In the discussion below, I will refer to a firm that is currently extracting and selling the resource as "active;" a firm that is not extracting is termed "inactive." While an

\footnotetext{
6 The assumption of identical initial reserves is made for expositional simplicity. For a model with heterogeneous firms, see Lozada (1996).
} 
inactive firm does not extract, it may still sell ore if it holds positive inventories.

Scale economies are introduced by assuming that extraction costs, $c\left(y_{i t}\right)$, are characterized by U-shaped average costs. The implication of this assumption is that no firm would willingly extract at a rate below minimum efficient scale, $y_{m}$, which minimizes average cost (Eswaran et al., 1983). Minimum efficient scale satisfies $y_{m} c^{\prime}\left(y_{m}\right)=c\left(y_{m}\right)$. Moreover, the marginal cost curve must be upward-sloping over the relevant range: $c^{\prime \prime}(y)>0$ for $y \geq y_{m}>0$. I also assume $c(0)=0$, but that instantaneously changing the extraction rate by a discrete amount yields a positive adjustment cost. ${ }^{7}$ For now, I assume storage is costless; I consider the implications of relaxing this assumption in section 6. Firm $i$ 's instantaneous profits at time $t$ are

$$
\pi_{i t}=P_{t}\left[y_{i t}-w_{i t}\right]-c\left(y_{i t}\right)
$$

writing the discount rate as $r$, firm $i^{\prime} s$ instantaneous discounted profits at time $t$ are

$$
\pi_{i t}^{d}=e^{-r t} \pi_{i t}
$$

Following Pindyck (1980), I assume that market price at instant $t$ is determined by ${ }^{8}$

$$
P_{t}=x_{t} f\left(Q_{t}\right)
$$

where $Q_{t}$ represents the instantaneous level of market sales, $f(\cdot)$ is the deterministic component of demand, and $x_{t}$ is the stochastic contribution to demand. The stochastic term is often modeled

\footnotetext{
7 As I noted in footnote 1, assuming such adjustment costs is equivalent to assuming that extraction rates are piecewise continuous, which rules out chattering controls.

8 In Pindyck's representation, $x$ influences both equilibrium price $P_{t}$ and equilibrium quantity $Q_{t}$.
} 
as geometric Brownian motion with drift; to highlight the role of uncertainty in the analysis, and avoid the complications introduced by having anticipated growth in demand, I assume there is no drift parameter. Thus, I assume $x$ follows the process

$$
\frac{d x}{x}=\sigma d z
$$

where $\mathrm{dz}$ is an increment of a standard Wiener process. ${ }^{9}$ Notice that $E[d x]=0$, although $E\left[d x^{2}\right]=$ $\sigma^{2} x^{2}$. To the extent that the stochastic component in demand causes the market clearing level of sales to fluctuate, prices will follow a stochastic path. ${ }^{10}$ Applying Itô's lemma, the evolution of prices can be described by (Pindyck, 1980, p. 1220): ${ }^{11}$

$$
E[d P]=x f^{\prime}(Q) E[d Q]+\frac{1}{2} x^{2} f^{\prime \prime}(Q) E\left[d Q^{2}\right]+f^{\prime}(Q) E[d Q d x]
$$

At each instant the state variables governing the decision problem are the level of the firm's reserves, its inventories, and the stochastic component of market price. The firm selects its extraction and inventory investment rates so as to maximize its expected discounted flow of profits, subject to the status of its mine and the stochastic processes governing the movement of prices.

\footnotetext{
9 That is, $\mathrm{dz}=\varepsilon[d t]^{1 / 2}$, where $\varepsilon$ is a serially uncorrelated normal random variable with mean zero and unitary variance.

10 In particular, price will be lognormally distributed (conditional on $Q$ ).

11 In light of footnote 8 , one anticipates $\frac{\partial Q}{\partial x}$ is positive (hence non-zero). Thus, Itô's lemma yields $E[d Q]=$ $\frac{\sigma^{2}}{2} \frac{\partial^{2} Q}{\partial x^{2}}, E\left[d Q^{2}\right]=\sigma^{2} x^{2}\left(\frac{\partial Q}{\partial x}\right)^{2}$, and $E[d Q d x]=\sigma^{2} x^{2} \frac{\partial Q}{\partial x}$ (Pindyck, 1980, Appendix A).
} 


\section{Characterization of the firm's solution}

Before studying the firm's optimizing decisions when demand is subject to stochastic shocks, I first analyze the deterministic problem. In this case, the firm's current value Hamiltonian is

$$
\mathbf{H}=P_{t}\left[y_{i t}-w_{i t}\right]-c\left(y_{i t}\right)-\lambda_{t} y_{i t}+\mu_{t} w_{i t},
$$

where $\lambda_{t}$ and $\mu_{t}$ are the current-value shadow prices of reserves and inventories, respectively. The maximum condition gives the necessary conditions for optimization:

$$
\begin{aligned}
& P_{t}-c^{\prime}\left(y_{i t}^{*}\right)-\lambda_{t}=0 ; \\
& P_{t}-\mu_{t}\left\{\begin{array}{l}
<0 \quad \Rightarrow \quad w_{i t}^{*}=y_{i t} \\
=0 \Rightarrow w_{i t}^{*} \text { is indeterminate; } \\
>0 \Rightarrow w_{i t}^{*}=-\infty(\text { respectively, }=0) \text { if } S_{i t}>0(\text { resp., }=0) ;
\end{array}\right. \\
& \dot{\lambda}_{t}=r \lambda_{t} ; \\
& \dot{\mu}_{t}=r \mu_{t} \text {. }
\end{aligned}
$$

Equations (9) and (10) indicate that prices must adjust so that rents appreciate at the rate of interest if the firm is to actively extract. The interpretation to equation (10) is that inventories will be liquidated (i.e., $w_{i t}=-\infty$ ) if current price exceeds the shadow value of inventories. This is intuitively compelling: once a unit of ore has been extracted, the firm may either sell it, earning $P_{t}$ immediately, or stockpile it, which yields an imputed present value of $\mu_{t}$. But this also holds true 
for any current stockpiles, and so all stockpiles will be immediately sold if $P_{t}>\mu_{t}$. By contrast, if the shadow price exceeds current price, all extracted ore will be stockpiled. When current price equals the shadow price, the firm is indifferent between any level of inventory adjustment.

The solutions to both differential equations governing the shadow values are exponential, with each shadow value growing at the rate $r$. Accordingly, if $\mu_{t}$ is not identically zero it must grow exponentially. If $\mu_{t}=0$ any inventories would be immediately eliminated; since the firm starts with no inventories, it will never hold any. Because equations (9) and (11) imply that prices rise at less than the rate of interest, if $\mu_{t}$ increases exponentially at the rate of interest then every firm would stockpile all extracted ore at each instant, in which event markets cannot clear. Thus, any equilibrium profile must preclude inventory holdings, and induce a price path that rises over time in such a manner that rents appreciate at the interest rate. ${ }^{12}$

Intuitively, if the firm were to hold stockpiles, it would possess two classes of stocks, inventories and in situ reserves. These stocks differ in terms of their extraction costs: selling from inventories is costless (since the extraction costs have already been paid), while reserves in the ground are costly to extract. In a deterministic setting, the optimal program must use up the lower cost reserves first. However, the only way inventories could exist in the first place is if excess extraction were to occur at some point in time, and so it follows that no inventories would ever be held.

This program would also be subject to a transversality condition, namely that the divergence between average profits and the shadow price of reserves would vanish at the terminal point in time:

$$
P_{T}-\frac{c\left(y_{i T}\right)}{y_{i T}}=\lambda_{T} .
$$

\footnotetext{
12 Eswaran et al. (1983) provide a formal argument establishing this point in their Appendix.
} 
Combined, equations (9) and (13) imply that the terminal extraction rate must be $y_{m}$. ELH's point is that this must be so for every firm, so that price will increase discontinuously just after instant $T$, implying that every firm could make arbitrage profits by delaying production until just after $T$. It follows that no rational expectations competitive equilibrium can exist in the deterministic case. ${ }^{13}$

Consider now the situation where demand is subject to stochastic shocks. Let the optimal value function for a firm with reserves of $R_{i t}$, inventories of $S_{i t}$, and with demand shock equal to $x_{t}$ at time $t$ be $\Omega\left(t, x_{t}, R_{i t}, S_{i t}\right)$. Because time only matters through discounting, the value function can be rewritten as $\Omega\left(t, x_{t}, R_{i t}, S_{i t}\right)=e^{-r t} V\left(x_{t}, R_{i t}, S_{i t}\right)$. Then, denoting partial derivatives by subscripts, the fundamental equation of optimality for a currently active firm is (Pindyck, 1980; Kamien and Schwartz, 1991):

$$
0=\max _{y_{i t}, w_{i t}} e^{-r t}\left\{P_{t}\left[y_{i t}-w_{i t}\right]-c\left(y_{i t}\right)-r V-y_{i t} \frac{\partial V}{\partial R}+w_{i t} \frac{\partial V}{\partial S}+\frac{1}{2} \sigma^{2} x_{t}^{2} \frac{\partial^{2} V}{\partial x^{2}}\right\} .
$$

As in the deterministic case, the optimal extraction rate for a firm that actively extracts at instant $t$ balances current rents against the shadow price of reserves in situ:

$$
P_{t}-c^{\prime}\left(y_{i t}^{*}\right)=\frac{\partial V}{\partial R}
$$

Of course, it is possible that demand shocks cause price to fall to a level such that extraction ceases. For combinations of $x$ and $R$ with $P_{t}-\frac{\partial V}{\partial R}<c^{\prime}\left(y_{m}\right)$, choosing the extraction rate that satisfies equation (15) would entail extracting at a rate less than minimum efficient scale. In this case, price is less than the full opportunity cost of a unit extracted. Hence, the contribution to the discounted flow of profits would be negative, and the firm would be better off by becoming inactive

\footnotetext{
13 As I noted in footnote 1, this conclusion presumes the firm cannot employ chattering controls; as these controls apparently have no practical significance this restriction eems on sound empirical ground.
} 
(i.e., by ceasing extraction). ${ }^{14}$ Also as in the deterministic case, the maximand is linear in $w_{i t}$, so that the optimal adjustments to inventories satisfy

$$
-P_{t}+\frac{\partial V}{\partial S}\left\{\begin{array}{lll}
<0 & \Rightarrow & w_{i t}^{*}=y_{i t} \\
=0 & \Rightarrow & w_{i t}^{*} \text { is indeterminate; } \\
>0 & \Rightarrow & w_{i t}^{*}=-\infty(\text { resp., }=0) \text { if } S_{i t}>0(\text { resp., }=0) .
\end{array}\right.
$$

If $P_{t}>\frac{\partial V}{\partial S}$ (so the shadow value of inventories is smaller than current price), the firm would wish to liquidate its inventories. If $P_{t}=\frac{\partial V}{\partial S}$, any value of $w_{i t}$ is optimal, so $w_{i t}$ is indeterminate. If $P_{t}<\frac{\partial V}{\partial S}$, the firm would wish to stockpile all extracted ore. Were this true for all firms, market price would rise, either without bound or to the choke price level, which would typically lead to positive sales (Bresnahan and Suslow, 1985). On the other side of the coin, should firms elect not to actively extract at any instant, the market can only clear if it is possible to sell from inventories.

It is instructive to think of the firm as solving a sequence of problems. At each instant $t$, the firm determines an optimal program, based on the current (and observed) demand shock. This consists of extraction and inventory plans for each future instant that maximize the discounted expected flow of profits, conditional on current demand, where the expectation is with respect to the future stream of prices. This program is subject to the anticipation that reserves will be exhausted at the terminal moment (Pindyck, 1980). Then in the next instant, a new demand shock is observed and the firm re-optimizes.

Because the optimal level of extraction will generally be a function of the stochastic state variable, as will the marginal value of reserves, there is no proper time derivative for either side

\footnotetext{
14 For a discussion of the firm's decision to shut down an active extraction program, or start extraction back up, see Mason (2001).
} 
of equation (15). Itô's differential operator, $\frac{1}{d t} E d[\cdot]$, which is the stochastic analog of the time derivative, is used in its place. Applying this operator to equation (15) yields:

$$
\frac{1}{\mathrm{dt}} E\left[\mathrm{~d}\left(P_{t}\right)\right]-\frac{1}{\mathrm{dt}} E\left[\mathrm{~d}\left(c^{\prime}\left(y_{i t}\right)\right)\right]=\frac{1}{\mathrm{dt}} E\left[\mathrm{~d}\left(\frac{\partial V}{\partial R}\right)\right]
$$

The analysis leading up to equation (12) in Pindyck (1980) can be applied here to show that $\frac{1}{\mathrm{dt}} E\left[\mathrm{~d}\left(\frac{\partial V}{\partial R}\right)\right]=r \frac{\partial V}{\partial R}$ and $\frac{1}{\mathrm{dt}} E\left[\mathrm{~d}\left(\frac{\partial V}{\partial S}\right)\right]=r \frac{\partial V}{\partial S} \cdot 15$ These relations are the stochastic analogues of the equations of motion for the co-state variables in the deterministic problem, eqs. (11) and (12).

$$
\begin{aligned}
\text { As } \frac{1}{\mathrm{dt}} E\left[\mathrm{~d}\left(\frac{\partial V}{\partial R}\right)\right]= & r \frac{\partial V}{\partial R} \text {, combining equations (15) and (17) yields } \\
& \frac{1}{\mathrm{dt}} E\left[\mathrm{~d}\left(P_{t}\right)\right]-\frac{1}{\mathrm{dt}} E\left[\mathrm{~d}\left(c^{\prime}\left(y_{i t}\right)\right)\right]=-r\left[P_{t}-c^{\prime}\left(y_{i t}\right)\right] .
\end{aligned}
$$

Equation (18) is the stochastic analog of Hotelling's rule: expected rents rise at the rate of interest. The second point, that $\frac{1}{\mathrm{dt}} E\left[\mathrm{~d}\left(\frac{\partial V}{\partial S}\right)\right]=r \frac{\partial V}{\partial S}$, implies $\frac{1}{\mathrm{dt}} E\left[\mathrm{~d}\left(P_{t}\right)\right]=r P_{t}$. Combining with equation (18), it follows that

$$
\frac{1}{\mathrm{dt}} E\left[\mathrm{~d}\left(c^{\prime}\left(y_{i t}\right)\right)\right]=r c^{\prime}\left(y_{i t}\right)
$$

along a path where the middle branch of eq. (16) applies.

In the deterministic case, extraction generally falls over time, so that one expects the time rate of change in marginal costs to be smaller than the present value of current marginal cost. Unlike the deterministic case, however, marginal costs can (temporarily) rise over time in the context of stochastic demand. Despite the overall tendency for production to decline over time,

15 The idea is to rewrite the fundamental equation of optimality as

$$
0=\max _{y_{i t}, w_{i t}}\left\{\pi_{i t}^{d}-r V+\frac{1}{\mathrm{dt}} E\left[\mathrm{~d}\left(V\left(x_{t}, R_{i t}, S_{i t}\right)\right)\right]\right\} .
$$

One can partially differentiate the fundamental equation of optimality with respect to any state variable; thus $0=$ $e^{-r t}\left\{\frac{\partial \pi_{i t}}{\partial Z_{i t}}-r \frac{\partial V}{\partial Z_{i t}}+\frac{1}{\mathrm{dt}} E\left[\mathrm{~d}\left(\frac{\partial V}{\partial Z_{i t}}\right)\right]\right\}$, for $Z_{i t}=R_{i t}, S_{i t}$. The expression in the text then follows from the fact that profits are independent of the two state variables. 
on average, the stochastic nature of extraction can yield an increase in anticipated marginal cost if the variation in extraction is sufficiently large, relative to the slope of marginal costs. This occurs because the optimal extraction rate is subject to a stochastic influence, which in turn means that marginal extraction cost will typically fluctuate. If there is enough variation in the demand shock, this can more than offset the reductions in extraction that will occur on average.

Making use of equations (15) and (16), the fundamental equation of optimality for an active firm at an interior solution may be simplified to:

$$
y_{i t} c^{\prime}\left(y_{i t}^{*}\right)-c\left(y_{i t}^{*}\right)-r V+\frac{\sigma^{2}}{2} x_{t}^{2} \frac{\partial^{2} V}{\partial x^{2}}=0
$$

The approach to solving such equations is to first obtain a general solution to the homogeneous component, and to then obtain any specific solution of the complete non-homogeneous equation (Boyce and DiPrima, 2005). This homogeneous equation is obtained from equation (20) by dropping the first two terms; the resultant differential equation is a linear second order ordinary differential equation, whose solution is of the form

$$
V^{h}=A x^{\eta_{0} t}+B x^{\eta_{1} t}
$$

The parameters $\eta_{0}$ and $\eta_{1}$ are the two roots to the quadratic form (Dixit and Pindyck, 1993)

$$
\frac{1}{2} \sigma^{2} \eta(\eta-1)-r=0
$$

It is straightforward to verify that one root (say $\left.\eta_{0}\right)$ is negative, while the other $\left(\eta_{1}\right)$ exceeds $r$. I argue below that the contribution to the optimal value function from $V^{h}$ must vanish as $x$ gets very large, so that $B$ must be zero. Thus, the solution to the homogeneous differential equation is 
the exponential

$$
V^{h}=A x^{\eta_{0} t}
$$

In this form, $A$ is constant with respect to the demand shock, though it can vary with either $R$ or $S$. Further, since the marginal value of an increase in the demand shock must be positive and $\eta_{0}$ is negative, it follows that $A<0$. Thus, the solution to the homogeneous differential equation is an increasing, concave function of $x$.

The solution is completed by specifying a particular solution, $V^{p}$. In the present case, this is non-trivial because the optimal extraction rate is implicitly determined by the state variables, via equation (15). Correspondingly, the particular solution will generally be a function of all three state variables; the general form for the optimal value function can thus be written as

$$
V(x, R, S)=V^{p}(x, R, S)+A(R, S) x^{\eta_{0} t} .
$$

Following the lines of Dixit and Pindyck (1993), one may argue that one candidate for a particular solution is the present expected discounted flow of profits (with respect to the path of future prices) for a firm which continues extracting until it exhausts its reserves and then sells off its inventories at an optimal rate. Whether the firm is extracting or not, the component of value associated with inventories is the stream of expected payments on deliveries out of inventories; because $\frac{1}{\mathrm{dt}} E\left[\mathrm{~d}\left(P_{t}\right)\right]=r P_{t}$, this expected stream can be collapsed into current price multiplied by the integral of future deliveries. But those future deliveries will sum to the current level of inventories, and so the contribution to value associated with the current inventory stock is just current price multiplied by current inventories, $P S .^{16}$

\footnotetext{
16 Similarly, the future stream of extractions must sum to current reserves. The expected present discounted flow of deviations between marginal and average cost weighted by optimal extraction summed with the product of current price and current stockpiles and the product of current reserves and current rents is then a plausible candidate as
} 
Using the present value of the expected discounted profit flow as the particular solution, the solution to the homogeneous component can be interpreted as the value of an option to optimally shut down an active mine (Dixit, 1989a,b). Observe that the value of an option to optimally close the mine must tend to zero as the demand shock gets very large, which explains why the coefficient $B$ in equation (21) must be zero. ${ }^{17}$ Likewise, the value of an option to shut down an exhausted mine must be zero, so that $A(0, S)=0$. Further, since the firm cannot extract after reserves have been liquidated, the sole contribution to the particular solution comes from the valuation of current stockpiles. Because the firm's optimal program when $R=0$ renders it indifferent between selling some of its inventories today and holding them for the future, so that the expected value of the optimal program equals $P S$, it follows that $\frac{\partial V}{\partial S}=P$ along this part of the path. As a result, any production profile is individually rational after reserves are exhausted, provided that positive inventories are held at the instant firms' reserves are exhausted. In particular, decision rules that draw down inventories at the precise rate so as to guarantee market clearing at each instant are consistent with optimizing behavior, and so can be part of a rational expectations equilibrium.

\section{Incentives to Stockpile}

A firm holding a unit of stockpiled ore has the option of selling it at instant $t$ or holding it for a brief period, and obtaining a capital gain. The opportunity cost of holding the inventory is the capitalized value of foregone sales, $r P_{t}$, while the expected capital gain is $\frac{1}{\mathrm{dt}} E\left[\mathrm{~d}\left(P_{t}\right)\right]$. If the latter is not smaller than the former, there will be an incentive to stockpile some ore (Pindyck, 1982,

a particular solution. See Dixit (1989b,a) and Dixit and Pindyck (1993) for further details and a derivation under similar, but greatly simplified, cases. The validity of the particular solution I propose is easy to establish in their circumstances, but messy in my model. A compelling argument that future values can be collapsed into current market values is forwarded by Lucas and Prescott (1971).

17 Dixit (1989a,b) uses a similar line of reasoning in his analysis. 
1994). Because rents are expected to rise at the rate of interest, it then follows that there will be an incentive to stockpile ore when

$$
\frac{1}{\mathrm{dt}} E\left[\mathrm{~d}\left(c^{\prime}\left(y_{i t}\right)\right)\right] \geq r c^{\prime}\left(y_{i t}\right)
$$

To evaluate this possibility, I expand the change in marginal costs and take expectations:

$$
E\left[d c^{\prime}\left(y_{i t}\right)\right]=c^{\prime \prime}\left(y_{i t}\right) E[d y]+\frac{1}{2} c^{\prime \prime \prime}\left(y_{i t}\right) E\left[d y^{2}\right]+\text { h.o.t. }
$$

where h.o.t. represents a remainder term of order larger than $E d y^{2}$. Using Itô's lemma, one may obtain

$$
\begin{aligned}
E[d y] & =\left[w_{i t} \frac{\partial y}{\partial S}-y_{i t} \frac{\partial y}{\partial R}+\frac{1}{2} \sigma^{2} x_{t}^{2} \frac{\partial^{2} y}{\partial x^{2}}\right] d t, \text { and } \\
E\left[d y^{2}\right] & =\sigma^{2} x_{t}^{2}\left(\frac{\partial y}{\partial x}\right)^{2} d t
\end{aligned}
$$

Inserting these relations into equation (25), dividing through by $d t$, and noting that the higher order terms go to zero faster than $d t$ gives the anticipated rate of change in marginal extraction costs:

$$
\frac{1}{\mathrm{dt}} E\left[\mathrm{~d}\left(c^{\prime}\left(y_{i t}\right)\right)\right]=c^{\prime \prime}\left(y_{i t}\right)\left[w_{i t} \frac{\partial y}{\partial S}-y_{i t} \frac{\partial y}{\partial R}\right]+\frac{1}{2} \sigma^{2} x_{t}^{2} c^{\prime \prime}\left(y_{i t}\right) \frac{\partial^{2} y}{\partial x^{2}}+c^{\prime \prime \prime}\left(y_{i t}\right) \sigma^{2} x_{t}^{2}\left(\frac{\partial y}{\partial x}\right)^{2}
$$

The condition governing the incentive to stockpile may therefore be written as

$$
-r c^{\prime}\left(y_{i t}\right)+c^{\prime \prime}\left(y_{i t}\right)\left[w_{i t} \frac{\partial y}{\partial S}-y_{i t} \frac{\partial y}{\partial R}\right]+\frac{\sigma^{2} x_{t}^{2}}{2}\left\{c^{\prime \prime}\left(y_{i t}\right) \frac{\partial^{2} y}{\partial x^{2}}+2 c^{\prime \prime \prime}\left(y_{i t}\right)\left(\frac{\partial y}{\partial x}\right)^{2}\right\} \geq 0
$$

which can be rewritten as $\sigma^{2} \geq \tilde{\sigma}_{t}^{2}$, where

$$
\tilde{\sigma}_{t}^{2}=\frac{r c^{\prime}\left(y_{i t}\right)-c^{\prime \prime}\left(y_{i t}\right)\left[w_{i t} \frac{\partial y}{\partial S}-y_{i t} \frac{\partial y}{\partial R}\right]}{\left[\frac{1}{2} c^{\prime \prime}\left(y_{i t}\right) \frac{\partial^{2} y}{\partial x^{2}}+c^{\prime \prime \prime}\left(y_{i t}\right)\left(\frac{\partial y}{\partial x}\right)^{2}\right] x_{t}^{2}} .
$$


Dividing both numerator and denominator by $c^{\prime}\left(y_{i t}\right)$ and rearranging yields

$$
\tilde{\sigma}_{t}^{2}=\frac{r-\varepsilon_{M C}\left[\frac{w_{i t}}{y_{i t}} \frac{\partial y}{\partial S}-\frac{\partial y}{\partial R}\right]}{\varepsilon_{M C}\left[\frac{y_{i t}}{2} \frac{\partial^{2} y}{\partial x^{2}}+\varepsilon_{M M C}\left(\frac{\partial y}{\partial x}\right)^{2}\right]\left(\frac{x_{t}}{y_{i t}}\right)^{2}},
$$

where $\varepsilon_{M C}=\frac{y_{i t} c^{\prime}\left(y_{i t}\right)}{c^{\prime \prime}\left(y_{i t}\right)}$ is the elasticity of marginal extraction cost with respect to the rate of extraction and $\varepsilon_{M M C}=\frac{y_{i t} c^{\prime \prime}\left(y_{i t}\right)}{c^{\prime \prime \prime}\left(y_{i t}\right)}$ is the elasticity of the slope of marginal extraction cost with respect to the rate of extraction.

Since reserves and inventories are substitute sources of sales, one expects $\frac{\partial y}{\partial S}<0$. On the other hand, one expects that firms will extract at a faster rate the larger are their reserves, and so $\frac{\partial y}{\partial R}>0$. With upward-sloping marginal costs, then, the numerator in the expression for $\tilde{\sigma}_{t}^{2}$ is positive. In light of equation (15), optimal extraction will be convex in the demand shock exactly when $\frac{\partial V}{\partial R}$ is concave in $x$, which is intuitively appealing; accordingly, the first term in the denominator is positive. So long as marginal cost is weakly convex in extraction, which is a mild restriction, the second term in the denominator is non-negative. Thus, one expects the square-bracketed term in the denominator to be positive. It follows that the threshold level of the variance on the demand shock is positive. This threshold is inversely related to the magnitude of the demand shock; alternatively, this expression can be manipulated to produce a lower bound for the variance in the spot price of the resource. So long as price is sufficiently volatile, then, there is an incentive to hold inventories. Finally, I note that $\tilde{\sigma}^{2}$ is increasing in $r$ and decreasing in the degree of convexity in extraction costs.

Consider now the firm's problem at any instant where there are no inventories. This could either be at the initial time, or at any later time after inventories have been liquidated. At such a time either $w>0$, which means inventories are being created, or $w=0$. In the latter case, there is 
a second critical level, $\tilde{\sigma}_{t}^{2}$, somewhat larger than $\tilde{\sigma}_{t}^{2}$, with the property that the expected increase in marginal costs will exceed the capitalized level of current marginal cost. ${ }^{18}$ If $\sigma^{2}>\tilde{\tilde{\sigma}}_{t}^{2}$, then (24) would be satisfied as a strict inequality at $w_{i t}=0$. It then follows that the firm would wish to select a positive level of $w_{i t}$, and so create inventories. Returning to equation (26), note that $\frac{1}{\mathrm{dt}} E\left[\mathrm{~d}\left(c^{\prime}\left(y_{i t}\right)\right)\right]$ is declining in $w_{i t}$; the optimal level of $w_{i t}$ sets $\frac{1}{\mathrm{dt}} E\left[\mathrm{~d}\left(c^{\prime}\left(y_{i t}\right)\right)\right]$ to the level where (24) is satisfied as an equality. ${ }^{19}$

Before turning to a discussion of equilibrium, I first note a crucial difference between this analysis and that of the deterministic model. When there are no demand shocks, the shadow price of inventories is identically zero, so that it never pays to add to inventories. In the stochastic version, on the other hand, the shadow price of inventories will generally not be zero. It is this distinction that allows the possibility that inventories will be held.

\section{Equilibrium conditions}

It is relatively simple to describe a rational expectations equilibrium in the deterministic case: it is a sequence of market prices that induce market clearing at each instant, given the entire path. In the stochastic variant, the notion of a rational expectations equilibrium requires both a sequence of prices that are based on equilibrium behavior and a sequence of expected price paths that are consistent with firms' plans and the underlying stochastic elements of the system. In principle, these paths can be constructed simultaneously (Lucas and Prescott, 1971), or an expected path

\footnotetext{
18 This parallels Pindyck (1982, p. 423). As in his model, the critical level in my model depends on various endogenous values in a complicated way.

19 The complete effect associated with this adjustment is somewhat more complicated. With all firms making these adjustments, deliveries to market are lowered. Accordingly, market price rises somewhat, which induces firms to raise their extraction levels. At the optimal combination of $y$ and $w$, equations (15) and (24) are both satisfied as equalities. In addition to the desire to smooth production, firms can be motivated to hold inventories to guard against 'stocking out.'
} 
can be built up from the proposed equilibrium path. Since the proposed equilibrium path is itself determined by the expected path, this boils down to determining a fixed point in a function from an infinitely dimensioned space into itself, generally a daunting task.

An important but subtle point here is that not only must firms hold inventories at every critical point in time, they must also be expected to do so. For this last condition to be met it is sufficient that they commence building up inventories at time 0 , and that they never liquidate them prior to the moment when reserves are exhausted.

Fortunately, in the case at hand, optimal extraction is based on a sequence of expected market clearing prices, and these prices in turn are determined by net sales at each instant. Suppose first that firms hold inventories at some time $t$. If current and expected future prices were such $r P>\frac{1}{\mathrm{dt}} E[\mathrm{~d}(P)]$, firms would wish to instantly liquidate their holdings. But this would depress market price, presumably to zero, so that the incentive to liquidate would be removed. On the other hand, if current and expected future prices were such $r P<\frac{1}{\mathrm{dt}} E[\mathrm{~d}(P)]$, firms would wish to devote all current extracted ore to their stockpiles. This would drive price to its choke level, which would remove the incentive to avoid sales. In the intermediate case,

$$
r P=\frac{1}{\mathrm{dt}} E[\mathrm{~d}(P)]
$$

and the firm is indifferent between any combination of sales and stockpiling. In particular, firms can do no better than unilaterally choosing sales rates that collectively guarantee market clearing at precisely the price satisfying equation (28).

As I noted above, the condition that firms are willing to hold inventories at all points in time may be represented as a condition on the variance in demand. Let $\mathrm{T}$ represent the largest possible date at which reserves are exhausted. (Since extraction is bounded away from zero, T must be 
finite.) Then, define $\bar{\sigma}^{2}=\max \left\{\tilde{\sigma}_{\tau}^{2}: 0 \leq \tau \leq T\right\}$. If $\sigma^{2} \geq \bar{\sigma}^{2}$, then it will pay to hold inventories at all moments when extraction is taking place. But the remarks at the end of section 5 indicate that holding inventories will then be individually rational while extraction has been suspended, or after reserves have been exhausted. It follows that a sequence of extraction and reserve additions can be found that solve each firm's dynamic optimization problem and that induce inventory holdings at all points in time.

Evidently, the viability of this explanation depends on the condition $\sigma^{2} \geq \bar{\sigma}^{2}$. Accordingly, the production smoothing motive is more likely to support equilibrium the smaller is $\bar{\sigma}^{2}$. Eq. (27) can be used to shed light on the impact of various parameters upon this possibility: The production smoothing argument is more compelling the smaller is $r$, the (risk-free real) rate of interest, or the larger is the elasticity of marginal cost with respect to the rate of extraction. These comparative effects are intuitive: smaller values of $r$ impose a smaller burden on production smoothing, while larger values of $\varepsilon_{M C}$ imply that changes in extraction rates have more pronounced impacts on the level of marginal costs, and hence increase the potential gains from smoothing production.

\section{Extensions}

The model in this paper embodies a handful of features that one might argue are unrealistic. First, I have implicitly assumed that the entire cost of production is born at the mine; in particular, extracted ore can instantly and costlessly be delivered to market. In reality, delivery costs are of substantial importance for various hard rock metals, uranium, and coal. ${ }^{20}$ Second, I have assumed

\footnotetext{
20 Relatedly, I have also assumed that there are no limits on the amount sent to market, as would occur if the means of delivery was subject to some overarching constraint (as with pipeline capacity constraints), nor have I allowed for a lag between extraction and sales, as one would expect if the ore must be refined prior to delivery. Incorporating delivery constraints into the model would require including an inequality constraint of the form $y-w \leq K$, with $K$ representing the delivery capacity. Adding in such a constraint would clutter the analysis somewhat, but could be employed as a means for exploring stock-out motives. Abel (1985) showed that competitive firms would generally have an incentive
} 
that extraction costs are independent of the amount of remaining reserves. Third, I have assumed that it is costless to hold inventories. In this section I describe the impact of relaxing each of these assumptions on the analysis, and argue that relaxing these assumptions does not undermine my central point: that a competitive rational expectations equilibrium can exist when demand is subject to sufficiently variable uncertainty.

Incorporating distribution costs into the model requires adding an extra term in the cost function. If delivery costs are linear in the amount sent to market, as would be the case were shipping costs based on a constant per-unit shipping price $t$, then deliver costs equal $t(y-w)$, and the current-value Hamiltonian becomes

$$
\mathbf{H}=\left(P_{t}-t\right)\left[y_{i t}-w_{i t}\right]-c\left(y_{i t}\right)-\lambda_{t} y_{i t}+\mu_{t} w_{i t} .
$$

As the state equations are not changed, one infers that net price (price less the per-unit charge $t$ ) must rise at the rate of interest to motivate inventory holdings, while positive extraction requires that "distribution rents" (net price less marginal extraction cost) rise at the rate of interest. As in the simpler model, satisfying both conditions is impossible in a deterministic setting, so that firms will not be motivated to hold inventories. Also as in the simpler model, there is a positive output at which the firm would cease extraction, generating a jump in price (and hence in net price), undermining equilibrium. In the stochastic setting, the fundamental equation of optimality to hold inventories when there is a production lag, while Blanchard and Fisher (1989) suggest that this motive may be at least as important as the production smoothing motive in explaining inventories of most commodities. Accordingly, allowing for delivery constraints or production lags would seem to strengthen the argument for inventory accumulation. While there are some similarities between my model and the existing literature on production smoothing, one key distinction is the context: the extant literature is largely tied to macroeconomic considerations, while I am focusing on a specific industrial application. 
becomes

$$
0=\max _{y_{i t}, w_{i t}} e^{-r t}\left\{\left[P_{t}-t\right]\left(y_{i t}-w_{i t}\right)-c\left(y_{i t}\right)-r V-y_{i t} \frac{\partial V}{\partial R}+w_{i t} \frac{\partial V}{\partial S}+\frac{1}{2} \sigma^{2} x_{t}^{2} \frac{\partial^{2} V}{\partial x^{2}}\right\}
$$

The optimality conditions for an interior solution correspond to eqs. (15) and (16) after subtracting out the per-unit transportation cost $t$ :

$$
\begin{aligned}
P_{t}-t-c^{\prime}\left(y_{i t}\right) & =\frac{\partial V}{\partial R} \\
P_{t}-t & =\frac{\partial V}{\partial S} .
\end{aligned}
$$

Stochastically differentiating these equations leads to the two conditions

$$
\begin{gathered}
\frac{1}{\mathrm{dt}} E\left[\mathrm{~d}\left(P_{t}-t\right)\right]-\frac{1}{\mathrm{dt}} E\left[\mathrm{~d}\left(c^{\prime}\left(y_{i t}\right)\right)\right]=\frac{1}{\mathrm{dt}} E\left[\mathrm{~d}\left(\frac{\partial V}{\partial R}\right)\right]=r \frac{\partial V}{\partial R}=r\left(P_{t}-t-c^{\prime}\left(y_{i t}\right)\right) ; \\
\frac{1}{\mathrm{dt}} E\left[\mathrm{~d}\left(P_{t}-t\right)\right]=\frac{1}{\mathrm{dt}} E\left[\mathrm{~d}\left(\frac{\partial V}{\partial S}\right)\right]=r \frac{\partial V}{\partial S}=r\left(P_{t}-t\right) .
\end{gathered}
$$

As before, one concludes that

$$
\frac{1}{\mathrm{dt}} E\left[\mathrm{~d}\left(c^{\prime}\left(y_{i t}\right)\right)\right]=r c^{\prime}\left(y_{i t}\right)
$$

along a path where the interior solutions apply. Also as before, the fundamental equation of optimality reduces to

$$
y_{i t} c^{\prime}\left(y_{i t}\right)-c\left(y_{i t}\right)-r V+\frac{\sigma^{2}}{2} x_{t}^{2} \frac{\partial^{2} V}{\partial x^{2}}=0
$$

at an interior solution. Thus, the analysis goes through much as before.

Incorporating stock effects into extraction costs induces three effects. First, there is a cosmetic change in the condition governing optimal extraction $\left(c^{\prime}(y)\right.$ is replaced with $\left.\frac{\partial c}{\partial y}\right)$. Second, the stochastic differential equation governing the evolution of the shadow price on remaining reserves 
is changed. The new version of this equation is

$$
\frac{1}{\mathrm{dt}} E\left[\mathrm{~d}\left(\frac{\partial V}{\partial R}\right)\right]=r \frac{\partial V}{\partial R}+\frac{\partial c}{\partial R}
$$

(As above, $\left.\frac{1}{\mathrm{dt}} E\left[\mathrm{~d}\left(\frac{\partial V}{\partial S}\right)\right]=r \frac{\partial V}{\partial S}\right)$. Third, the stochastic differential equation governing the evolution of marginal costs is changed. The new version of this equation is

$$
\frac{1}{\mathrm{dt}} E\left[\mathrm{~d}\left(\frac{\partial c}{\partial y}\right)\right]=\frac{\partial^{2} c}{\partial y_{i t}^{2}}\left[w_{i t} \frac{\partial y}{\partial S}-y_{i t} \frac{\partial y}{\partial R}\right]+\frac{1}{2} \sigma^{2} x_{t}^{2} \frac{\partial^{2} c}{\partial y_{i t}^{2}} \frac{\partial^{2} y}{\partial x^{2}}+\frac{\partial^{3} c}{\partial y_{i t}^{3}} \sigma^{2} x_{t}^{2}\left(\frac{\partial y}{\partial x}\right)^{2}-\frac{\partial^{2} c}{\partial y_{i t} \partial R_{t}} y_{i t} .
$$

Accordingly, the key condition motivating the holding of inventories when extraction costs are stock-dependent is $\sigma^{2} \geq \hat{\sigma}^{2}$, where:

$$
\hat{\sigma}_{t}^{2}=\frac{r+\left[\frac{\partial^{2} c}{\partial y_{i t} \partial R_{t}} y_{i t}-\frac{\partial c}{\partial R}\right] / \frac{\partial c}{\partial y}-\varepsilon_{M C}\left[\frac{w_{i t}}{y_{i t}} \frac{\partial y}{\partial S}-\frac{\partial y}{\partial R}\right]}{\varepsilon_{M C}\left[\frac{y_{i t}}{2} \frac{\partial^{2} y}{\partial x^{2}}+\varepsilon_{M M C}\left(\frac{\partial y}{\partial x}\right)^{2}\right]\left(\frac{x_{t}}{y_{i t}}\right)^{2}} .
$$

The influence of stock dependency in costs upon the cutoff value of variance depends on the sign of $\frac{\partial^{2} c}{\partial y_{i t} \partial R_{t}} y_{i t}-\frac{\partial c}{\partial R}$. One expects $\frac{\partial^{2} c}{\partial y_{i t} \partial R_{t}}<0$ and $\frac{\partial c}{\partial R}<0$ when costs are stock-dependent (both total and marginal cost increase as stocks are depleted), so the sign of this term is ambiguous. But if costs take the form $c(y, R)=\gamma(y) / R$, as in Pindyck (1980), then the sign of this new term depends on the sign of $\gamma^{\prime}(y)-\frac{\gamma(y)}{y}$. This term corresponds to the difference between marginal and average costs in the simpler model, which was assumed to be positive. Adopting such an interpretation in this context, the presence of stock-dependency in extraction costs would lower the requisite volatility in resource prices to motivate the holding of inventories.

Finally, suppose it is costly to hold inventories. These costs could reflect, for example, the costs associated with maintaining the stockpile (e.g., labor costs associated with monitoring the stockpile, or insurance costs linked to the volume held in hand); they seem less likely to depend 
on the rate of change in inventories. ${ }^{21}$ Accordingly, inventory costs can be expressed as $c_{I}(S)$. Introducing inventory costs induces two complications. The first is the potential for such costs to outweigh any gains associated with holding inventories, thereby destroying the motive to hold inventories. Thus, for the central result discussed above to survive the inclusion of inventory costs it must be the case that

$$
V(x, R, S)-V(x, R, 0) \geq c_{I}(S)
$$

for all values of $x, R$ and $S$. From the discussion above, the left-hand side of (30) equals $P S$, and so the comparison of interest reduces to

$$
P \geq c_{I}(S) / S
$$

i.e. if market price exceeds the average cost of holding inventories. If the condition (31) were to fail for some combination of the state variables, then it would no longer be the case that inventories would be held (and anticipated) for all levels of price and $S$, and so one would have to fall back on the sorts of arguments described in the introduction to resurrect a case for the existence of a competitive equilibrium. That noted, condition (31) will hold naturally if average costs are bounded above, as would be the case were there no fixed costs $\left(c_{I}(0)=0\right){ }^{22}$

More fundamentally, including inventory costs changes the equation of motion for the marginal value of inventories. Adapting the discussion in footnote 15, the fundamental equation of optimality becomes:

$$
0=\max _{y_{i t}, w_{i t}}\left\{e^{-r t}\left[P_{t}\left(y_{i t}-w_{i t}\right)-c\left(y_{i t}\right)-c_{I}(S)\right]+\frac{1}{\mathrm{dt}} E\left[\mathrm{~d}\left(\Omega\left(x_{t}, R_{i t}, S_{i t}\right)\right)\right]\right\} .
$$

\footnotetext{
21 Indeed, Considine (1997) finds that inventory costs for crude oil are not statistically influenced by inventory adjustments.

22 Even if there were fixed costs associated with holding inventories, this condition could still hold if prices rose sufficiently rapidly. Because prices are expected to rise at the rate of interest, this constraint does not seem particularly restrictive.
} 
Partially differentiating with respect to $S$ then gives $0=e^{-r t}\left\{-c_{I}^{\prime}(S)-r \frac{\partial V}{\partial S}+\frac{1}{\mathrm{dt}} E\left[\mathrm{~d}\left(\frac{\partial V}{\partial S}\right)\right]\right\}$, so that $\frac{1}{\mathrm{dt}} E\left[\mathrm{~d}\left(\frac{\partial V}{\partial S}\right)\right]=r \frac{\partial V}{\partial S}+c_{I}^{\prime}(S)$. (As above, $\frac{1}{\mathrm{dt}} E\left[\mathrm{~d}\left(\frac{\partial V}{\partial R}\right)\right]=r \frac{\partial V}{\partial R}$.) Accordingly, the condition governing the incentive to stockpile when it is costly to hold inventories is $\sigma_{2} \geq \hat{\hat{\sigma}}_{t}^{2}$, where

$$
\hat{\hat{\sigma}}_{t}^{2}=\frac{r+\frac{c_{I}^{\prime}(S)}{c^{\prime}\left(y_{i t}\right)}-\varepsilon_{M C}\left[\frac{w_{i t}}{y_{i t}} \frac{\partial y}{\partial S}-\frac{\partial y}{\partial R}\right]}{\varepsilon_{M C}\left[\frac{y_{i t}}{2} \frac{\partial^{2} y}{\partial x^{2}}+\varepsilon_{M M C}\left(\frac{\partial y}{\partial x}\right)^{2}\right]\left(\frac{x_{t}}{y_{i t}}\right)^{2}} .
$$

The comparative effects of various parameters are much as above, with the additional feature that increases in marginal inventory costs lower the likelihood that production smoothing will motivate inventory holdings. This result is, of course, to be expected: all else equal, higher opportunity costs of inventories should make them less desirable. That said, it remains true that sufficiently large variability in demand can motivate holding inventories, even if it is costly to do so.

\section{Concluding Remarks}

It may seem counter-intuitive that a firm holding both reserves and inventories would be willing to simultaneously extract and stockpile, as in situ reserves are higher cost to develop than are stockpiles. Indeed, such simultaneous activities cannot be part of an optimal program under deterministic conditions. But this need not be the case in a stochastic environment. In particular, it can pay the firm to use up its higher cost reserves first, holding the lower cost reserves until a later date when demand is stochastic (Slade, 1988). This is one interpretation of behavior in my model: firms hold onto the lower cost inventory reserves, electing not to sell them until after the higher cost (in situ) reserves are exhausted. While extraction falls discontinuously from $y_{m}$ to 0 at the instant reserves are vanquished, sales adjust smoothly, allowing a competitive rational expectations equilibrium to exist.

At the end of the day, it is an empirical matter whether inventory holdings can facilitate 
the existence of competitive equilibria in markets for non-renewable resources characterized by non-convex extraction costs. On this point, I offer some casual empirical evidence. Figure 2 plots average monthly values of extraction, sales and inventories for three energy resources (crude oil, natural gas and coal). ${ }^{23}$ While there are some differences between the pattern of these plots across resources (notably, sales of natural gas and coal exhibit important seasonal patterns), two broad features appear to hold consistently. First, the variation in extraction levels is generally smaller than the variation in sales. This feature is consistent with the notion that firms hold inventories to smooth production, since such a motive would allow swings in sales to be partially offset by inventory adjustments. Second, though occasionally subject to relatively wide swings, inventory levels are generally significant across time. This feature suggests that inventories are motivated by considerations that are likely to persist over time, as opposed to transitory consideration. In turn, this underscores the importance of inventories as an empirical phenomenon.

To elaborate on the visual data contained in Figure 2, I provide summary statistics for a range of resources in Table $1 .{ }^{24}$ In part A, I report average annual values and standard deviations for extraction levels, inventory holdings, and real prices across a range of resources. Because large standard deviations could reflect nothing more than large overall values, I also report the coefficient of variation - the ratio of standard deviation to mean value-for extraction, inventories and real prices, for each of 16 resources. For some energy resources, more refined data are available, and so in part B I report monthly values of the elements appearing in part A of the Table. ${ }^{25}$ In general,

\footnotetext{
23 All data are drawn from the U.S. Energy Information Administration website, which can be accessed at http://www.eia.doe.gov/. While it is conceivable these resources are special, I believe the broad pattern of results illustrated in Figure 2 is suggestive of the likely empirical importance of the production smoothing motive for holding inventories. The statistics reported in Table 1, discussed below, are generally consistent with the visual impressions drawn from Figure 2.

24 Data are taken from the U.S. Geologic Survey website, which can be accessed at http://minerals.usgs.gov/minerals/pubs/commodity/. This website provides access to data for scores of resources; I selected resources with relatively long sample periods without missing observations.

25 As monthly data on coal prices are not available, I report statistics for daily NYMEX prices for Appalachian
} 
inventory holdings are significant for these resources, both in absolute terms and in relation to average production rates. Average inventory holdings range from a low of .023 years' worth, or roughly 8.5 days, (Soda Ash) to a high of 15.9 year's worth (Helium). Inventories for most resources are in the range of .2 to .9 years' worth. Further, there is some evidence that average inventory holdings are correlated with variability in real prices - the simple correlation coefficient between average inventory holdings and the coefficient in variation of real prices is 0.18 . Finally, if one sorts resources into four groups of four by the coefficient in variation of spot prices, the mean level of average inventory holdings is 3.28 years' worth for the top quartile (the group with the highest variation in price), .33 for the second quartile, .21 for the third quartile, and .44 for the bottom quartile (the group with the highest variation in price); the difference between the mean for the top quartile and the other resources is statistically significant at the $5 \%$ level, while the mean values for the other three quartiles are not statistically different from one another. This evidence is at least broadly consistent with the hypothesis that greater level of price variation induce greater inventory holdings, a phenomenon implied by the production smoothing model. ${ }^{26}$

It is interesting to compare the mechanism promoting equilibrium in my model with the contestability argument offered by Asheim (1992) and Cairns (1991). For contestability to rationalize equilibrium, one must imagine there are a group of potential sellers who stand ready to enter

coal. Data for crude oil are for West Texas Intermediate spot prices, while data for natural gas are Henry's Hub spot prices. The U.S. Energy Information Administration website reports nominal prices; these were converted to real prices using the Consumer Price Index.

26 These results are consistent with findings in the extant literature for specific resources (Considine and Larson, 2001; Pindyck, 1994). That noted, it seems likely that there is more going on here than just the intention to smooth production. For example, one sees similar inventory patterns across the three energy resources in part B, despite the fact that oil prices appear to be more volatile. In part this could reflect differences in storage costs, but I suspect it also reflects the fact that natural gas and coal markets are subject to seasonal variability, a feature that I have ignored in the model; one might interpret this element as generating a stock-out motive for inventory holding. In addition, the U.S. Geologic Survey website excises observations for some resources, indicating that reporting these data would raise confidentiality concerns. Presumably, this reflects a situation where there are a small number of firms, i.e. an oligopoly. 
the market at a moment's notice if prices rise rapidly (as would happen at the critical juncture in Eswaran et al. (1983)). While the logic on the underlying strategic story is not in question, I think the empirical validity of that scheme is. One is hard put to come up with examples where firms dance in and out of the market in the fashion associated with contestable markets (c.f. footnote 3). But the presence of firms holding inventories provides an alternative mechanism whereby firms can rapidly add to market production in a manner that seems spiritually similar to contestable markets. With inventories, the 'firm' that potentially practices 'hit and run entry', to borrow a phrase from the early literature on contestability, is any firm holding inventories-whether they are presently extracting the resource or not. In this regard, one might view the inventory argument as providing a more empirically plausible illustration of the contestability mechanism. 


\section{References}

Abel, A. (1985). Inventories, stockouts, and production smoothing, Review of Economic Studies 52: $283-194$.

Arrow, K. J., Karlin, S. and Scarf, H. (1958). Studies in the mathematical theory of inventory and production, Stanford University Press, Palo Alto CA.

Asheim, G. B. (1992). Contestability in a resource market with non-convex costs, Scandinavian Journal of Economics 94: 609-618.

Blanchard, O. J. and Fisher, S. (1989). Lectures on Macroeconomics, MIT Press, Cambridge, MA.

Boyce, W. E. and DiPrima, R. C. (2005). Elementary differential equations and boundary value problems, 8th edn, John Wiley, New York.

Bresnahan, T. F. and Suslow, V. Y. (1985). Inventories as an asset: the volatility of copper prices, International Economic Review 26: 409-424.

Cairns, R. D. (1991). On non-convex costs and dynamic consistency in an exhaustible resource market, Scandinavian Journal of Economics 93: 89-100.

Cairns, R. D. (2008). Exhaustible resources, non-convexity and competitive equilibrium, Environmental and Resource Economics 40: 177-193.

Considine, T. J. (1997). Inventories under joint production: Am empirical analysis of petroleum refining, Review of Economics and Statistics 79: 493-502.

Considine, T. J. and Larson, D. F. (2001). Risk premiums on inventory assets: The case of crude oil and natural gas, The Journal of Future Markets 20: 109-126. 
CRA (1977). Uranium price formation, Technical Report EA-498, Electric Power Research Institute.

Dixit, A. (1989a). Entry and exit decisions under uncertainty, Journal of Political Economy 97: 620-638.

Dixit, A. (1989b). Hysteresis, import penetration, and exchange rate pass through, Quarterly Journal of Economics 104: 205-228.

Dixit, A. and Pindyck, R. (1993). Investment under uncertainty, Princeton University Press, Princeton, NJ.

Eswaran, M., Lewis, T. R. and Heaps, T. (1983). On the nonexistence of market equilibria in exhaustible resource markets with decreasing costs, Journal of Political Economy 91: 154-167.

Fisher, A. C. and Karp, L. S. (1993). Nonconvexity, efficiency and equilibrium in exhaustible resource depletion, Environmental and Resource Economics 3: 97-106.

Fisher, C. (2005). Competition in markets for depletable resources with setup costs, Environmental and Resource Economics 30(3): 243-257.

Hartwick, J. M., Kemp, M. C. and Long, N. V. (1986). Set-up costs and theory of exhaustible resources, Journal of Environmental Economics and Management 13: 211-224.

Hotelling, H. (1931). The economics of exhaustible resources, Journal of Political Economy 39: $137-175$.

Kamien, M. and Schwartz, N. (1991). Dynamic Optimization: The Calculus of Variations and Optimal Control in Economics and Management, North Holland, Amsterdam. 
Lozada, G. A. (1996). Existence of equilibria in exhaustible resource industries: Nonconvexities and discrete vs. continuous time, Journal of Economic Dynamics and Control 20: 433-444.

Lucas, R. E. J. and Prescott, E. C. (1971). Investment under uncertainty, Econometrica 39: 659681.

Mason, C. F. (1989). Exploration information and aec regulation of the domestic uranium industry, Journal of Economic Dynamics and Control 13: 421-448.

Mason, C. F. (2001). Nonrenewable resources with switching costs, Journal of Environmental Economics and Management 42: 65-81.

Oleweiler, N. D. (1981). Capacity constraints and destructive competition in the extraction of non-renewable natural resources, Technical report, Queen's University.

Pindyck, R. S. (1980). Uncertainty and exhaustible resource markets, Journal of Political Economy 88: $1203-1225$.

Pindyck, R. S. (1982). Uncertainty and the behavior of the firm, American Economic Review 72: 415-427.

Pindyck, R. S. (1994). Inventories and the short run dynamics of commodity prices, RAND Journal of Economics 25: 141-159.

Slade, M. (1988). Grade selection under uncertainty: Least cost last and other anomalies, Journal of Environmental Economics and Management 15: 189-205.

Thurman, W. N. (1988). Speculative carryover: an empirical explanation of the u.s. refined copper market, RAND Journal of Economics 19: 420-437. 
Williams, J. C. and Wright, B. D. (1991). Storage and Commodity Markets, Cambridge University Press, Cambridge, UK.

Zimmerman, M. B. (1977). Modeling depletion in a mineral industry: the case of coal, Bell Journal of Economics 8: 41-65. 

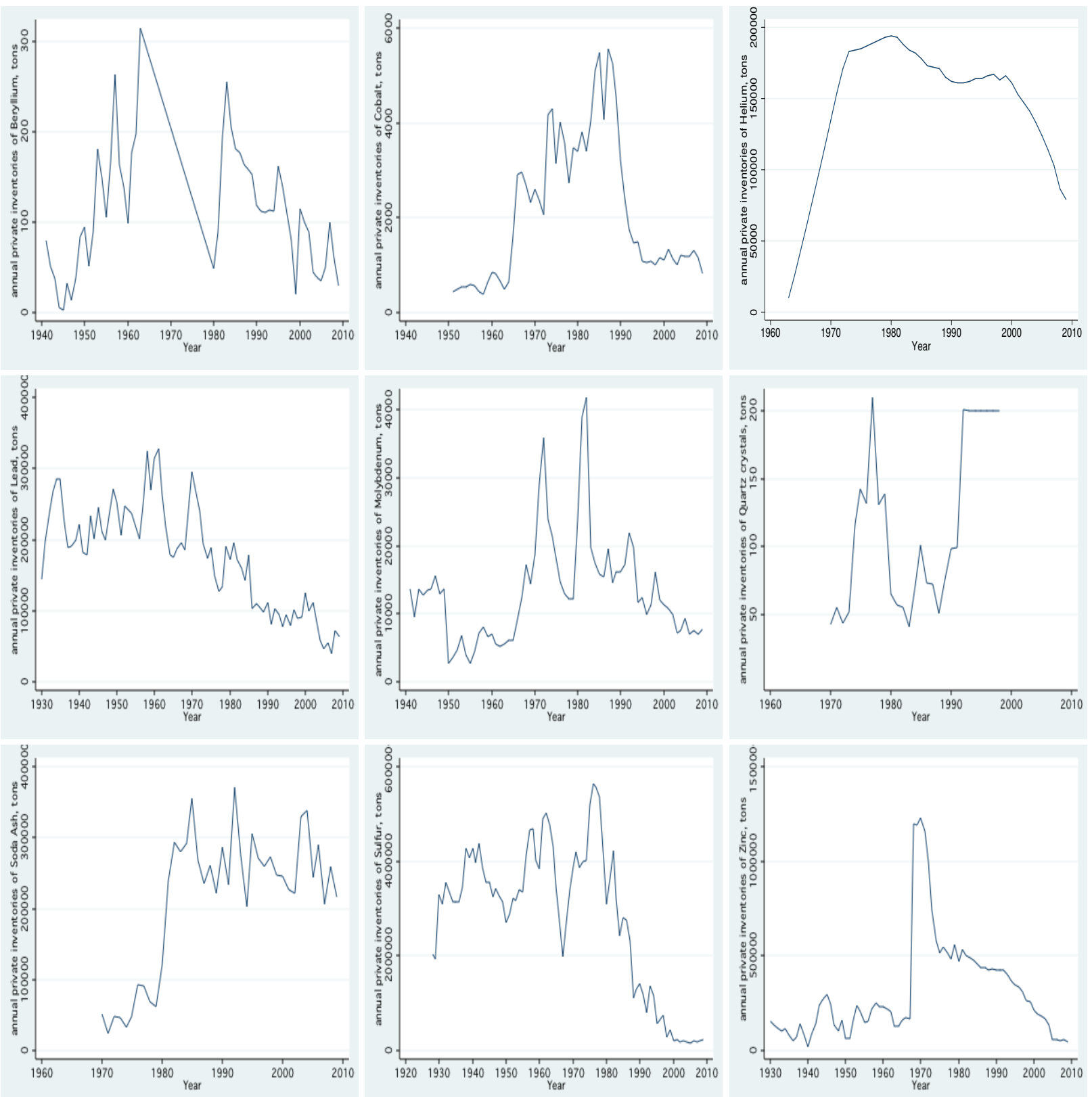

Figure 1: Annual private inventories, various resources 

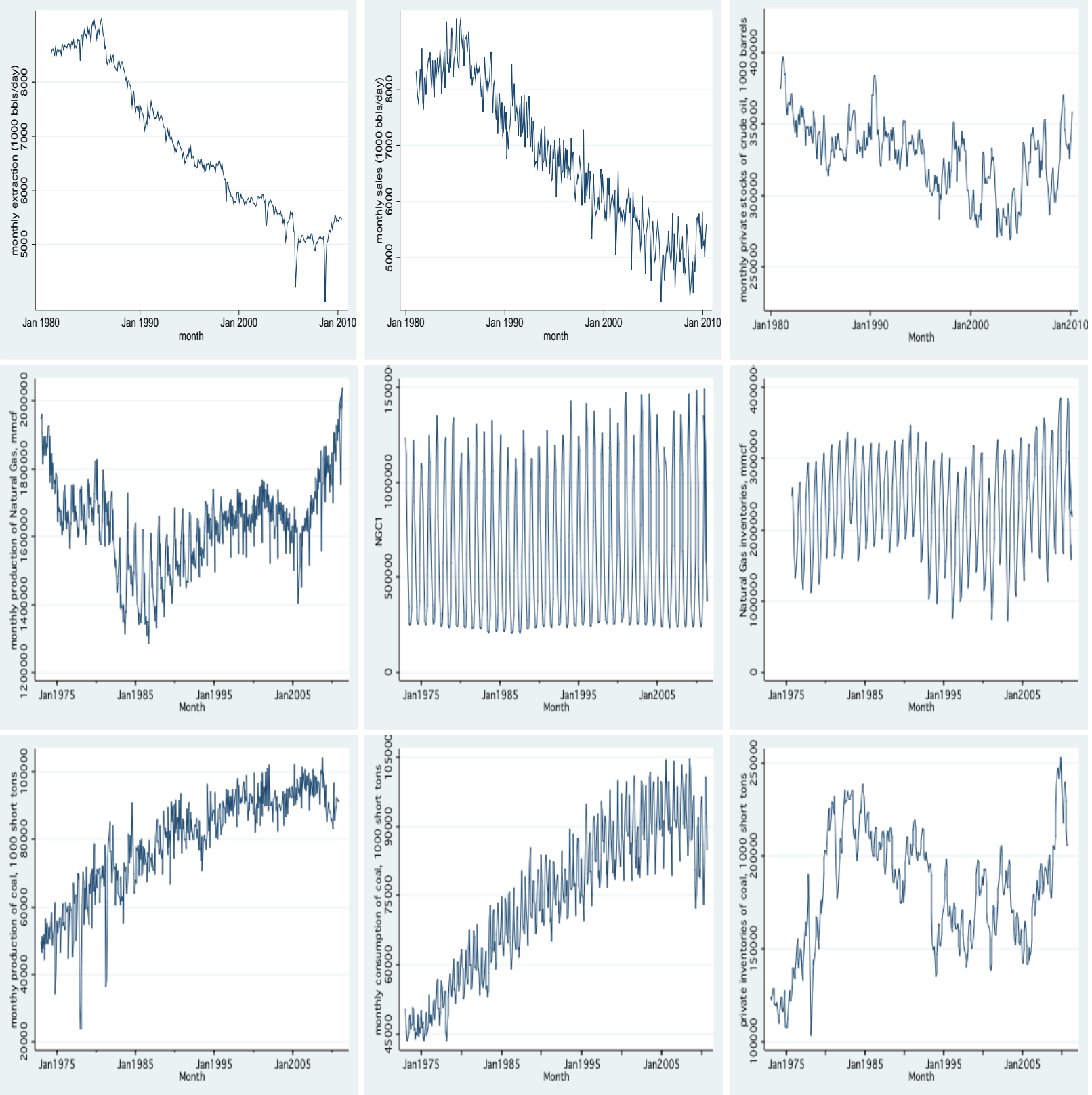

Figure 2: extraction (left), sales (center) and inventories (right): crude oil, natural gas and coal 


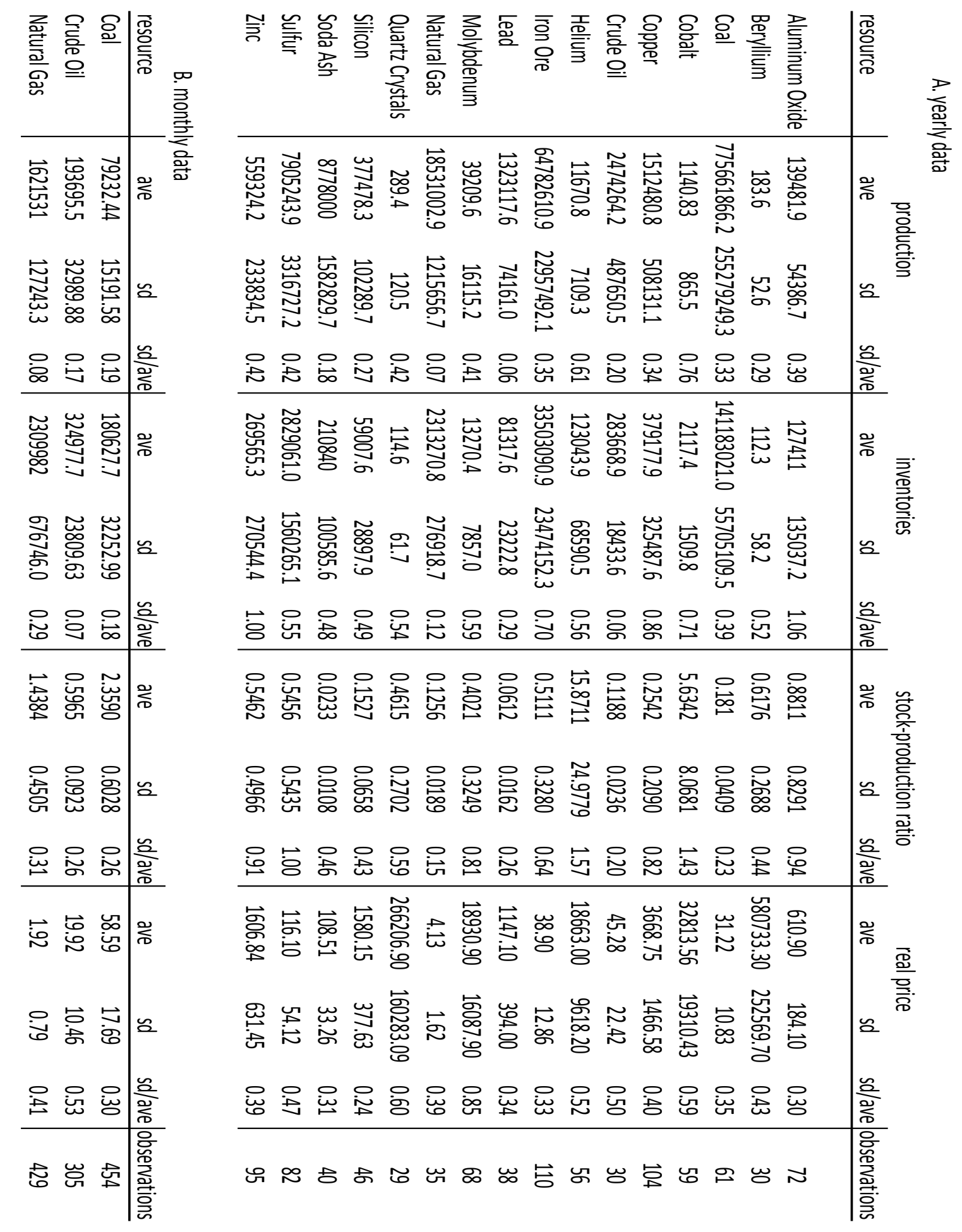

Table 1: production, inventories and prices for various resources 